\section{Sopro de vida: experiência com a doença pulmonar obstrutiva crônica na pobreza urbana de Fortaleza, Ceará, Brasil}

\author{
Breath of life: experience with chronic obstructive \\ pulmonary disease in the context of urban \\ poverty in Fortaleza, Ceará State, Brazil
}

\author{
${ }_{1}$ Programa de Pós-graduação \\ em Saúde Coletiva, \\ Universidade de Fortaleza, \\ Fortaleza, Brasil. \\ 2 Department of Global \\ Health and Social Medicine, \\ Harvard University Medical \\ School, Boston, U.S.A. \\ Correspondência \\ J. M. S. Pinto \\ Programa de Pós-gradu- \\ ação em Saúde Coletiva \\ Universidade de Fortaleza. \\ Rua Dr. Hermes Lima 106, \\ Fortaleza, $C E$ \\ 60811-570, Brasil. \\ jumsp@hotmail.com
}

\section{Abstract}

This is an anthropological study on the experience of living with chronic obstructive pulmonary disease (COPD) for low-income individuals in the city of Fortaleza, Ceará State, Brazil. From March to November 2006, we conducted case studies of six patients, using ethnographic interviews, illness narratives, and participantobservation during hospital treatment and home visits. Thematic context analysis and contextualized semantic analysis were used to link individual experience to system of significance, actions taken, and structural constraints. Based on the findings, COPD provokes subjective sensations, signs, and meanings. The diagnosis "smothers" patients, provoking hardships and limitations in their manual, sexual, domestic, family, and leisure activities. Lay strategies used to confront acute shortness of breath and low self-esteem include: avoiding direct contact with the patient's "phlegm", quitting or reducing smoking, treating symptoms with home remedies and popular body therapies, remaining calm during attacks, rejecting imposed therapies, and surrendering one's self to spiritual powers. Thus, the subjectivity of illness cannot be excluded from the measurement of the "global burden of disease" in Northeast Brazil.

Chronic Obstructive Pulmonary Disease; Illness; Cultural Anthropology
Juliana Maria de Sousa Pinto 1

Luiza Jane Eyre de Souza Vieira 1

Marilyn K. Nations 1,2

\section{Introdução}

A educação em saúde, a elaboração de políticas públicas saudáveis para a promoção da saúde, a participação ativa do paciente, a convivência equilibrada com sua doença e a internalização do sentido de empowerment são desafios do atual paradigma do cuidado na saúde $1,2,3,4,5,6,7,8$. No acompanhamento de doenças crônicas como a doença pulmonar obstrutiva crônica, a co-responsabilização dos sujeitos é imprescindível 5; os pacientes freqüentemente não aderem às recomendações médicas de realizar atividade física 9 , seguir a terapêutica medicamentosa ou abandonar o tabagismo 10. Entretanto, pelo olhar crítico do paciente 11 , baseado na racionalidade leiga, a "não adesão" à intervenção terapêutica pode ser interpretada como um protesto contra um tratamento que agride seu modo de pensar e agir no mundo e não um simples não-cumprimento de ordens médicas 12,13.

Médicos antropólogos 14 argumentam que respostas sócio-culturais às doenças crônicas muitas vezes são incompreensíveis aos profissionais responsáveis pelo manejo clínico. As racionalidades subjacentes da condição crônica são conflitantes entre quem cuida e quem é cuidado. O profissional define doença pulmonar obstrutiva crônica como processo patológico que limita o fluxo aéreo, embora tratável. Não é totalmente reversível; é usualmente progressiva e associada a uma inflamação pulmonar anormal às partí- 
culas nocivas de gases primariamente causadas pelo cigarro ${ }^{15}$.

Diferentemente, a pessoa doente, a família e a sociedade convivem e respondem aos sintomas e incapacidades deixados pela doença. Essa experiência da enfermidade ou illness 16 inclui maneiras de explicar, no senso comum, as angústias causadas pelos processos fisiopatológicos. O julgamento do paciente sobre como melhor lidar com as angústias e problemas do cotidiano relacionados à cronicidade está embutido nos sentidos e significados do mundo local moral 17. Jamais são compreensíveis isolados do contexto macrossocial. Não se pode desconsiderar no tratamento das doenças crônicas a cultura, as crenças 18,19, o saber popular 20,21 e a realidade sócio-econômica e política do sujeito ${ }^{22}$. A subjetividade, convivência e experiência com a doença, dificuldades e sofrimentos impostos pela violência institucional durante a hospitalização prolongada são fatores críticos na construção da enfermidade (illness) 23,24.

Para se compreender o adoecimento de pessoas com doença pulmonar obstrutiva crônica é necessário considerar a subjetividade do sujeito no cuidado. O estudo antropológico é relevante aqui 25 porque o comportamento humano tem uma dimensão expressiva 26. Esses estudos desvelam a realidade social resgatando a dimensão vivida da cultura 27 . Por intermédio da narrativa da enfermidade a "voz" do paciente é revelada e o pesquisador aproxima a doença à realidade ambiental, social, econômica e cultural vivida pelo doente, mantendo a harmonia com os eventos distintivos e o curso do sofrimento 16 . Contextualizar a experiência humana da doença pulmonar obstrutiva crônica é crucial devido à sua abordagem biomédica enfatizar o processo patológico e fatores de risco restritos. Ampliando essa visão, este trabalho recorre à Antropologia Médica para compreender dificuldades, sofrimentos e estratégias populares utilizadas no enfrentamento desta doença na pobreza do Nordeste brasileiro com base na narrativa da experiência vivenciada pelo paciente.

\section{Metodologia: experiência da enfermidade contextualizada}

Entre março e novembro de 2006, esta pesquisa antropológica foi realizada no Programa de Reabilitação Pulmonar de um hospital público de Fortaleza (2.200.000 habitantes), capital do Estado do Ceará, no Nordeste brasileiro, região metropolitana marcada pela pobreza, disparidade econômica, desigualdades, segregação social 28 , violência institucional 11,24 e crescente vulnerabi- lidade pessoal. De 1991 a 2000, a distância média entre os $10 \%$ mais ricos e os $40 \%$ mais pobres em Fortaleza cresceu de 13,3 para 18,7 vezes 28 ; a taxa de homicídios foi de $35,4 \%$ do total de habitantes em 200629.

Dentre os 15 pacientes do Programa de Reabilitação Pulmonar no período da coleta dos dados, seis foram selecionados para estudo em profundidade pela gravidade da sua doença e dependência do uso de oxigênio suplementar. Quatro participam há quatro anos do programa, demonstrando conhecimento das ações educativas; dois são iniciantes sem experiência prévia. Embora o foco neste artigo seja desvelar a visão crítica do paciente com doença pulmonar obstrutiva crônica, consideramos a do cuidador quando relevante.

A idade dos informantes-chave variou entre 37 e 69 anos, com média de 56,5 anos. A metade (50\%) é homem; a maioria (66,6\%) é casada e conta com o apoio do cônjuge no manejo da doença; 2 (33,3\%) são viúvas. Cada paciente tem entre 4 e 12 filhos que costumam ajudar durante as crises. Todos (100\%) residem em favelas, conjuntos habitacionais ou bairros periféricos, pertencem à classe sócio-econômica de baixa renda e são inativos economicamente; $66,6 \%$ migraram do interior. Os três homens são legalmente aposentados, recebem uma pensão de um salário mínimo ( $\mathrm{R} \$ 350,00$ em 2006) por invalidez. As três mulheres são donas-de-casa, mas não executam suas tarefas nem recebem benefícios do governo, são sustentadas por outros. Quanto à escolaridade, $11,1 \%$ têm menos de três anos de estudo; $66,6 \%$ terminaram o Ensino Fundamental e 33,3\% o Ensino Médio. Embora todos tenham declarado uma religião (66,6\% católicos e 33,3\% evangélicos), somente $50 \%$ praticam sua fé.

Para situar o paciente dentro do seu universo de significação 18, utilizamos "estudos de casos ricos em informação" (information rich case studies) 30, a entrevista etnográfica 31, a narrativa da enfermidade 16,32 e a observação participante para construir uma "descrição densa" 18 da experiência com a doença pulmonar obstrutiva crônica. Após contato inicial no hospital foram realizadas visitas domiciliares. Entrevistas etnográficas foram conduzidas utilizando-se um guia de tópicos a serem explorados, além do incentivo à narração livre da experiência com a doença pulmonar obstrutiva crônica. A coleta de dados na própria residência deixou o paciente à vontade para expressar idéias e estabeleceu rapport (elo afetivo) entre as pesquisadoras, aproximando-as da realidade sócio-cultural e ambiental dos pacientes. A entrevista foi norteada por perguntas abertas: "Descreva sua doença para mim."; "O que acontece quando tem 
uma crise?”; "Que você acha que é a causa do seu problema?”; "Quais são as dificuldades que você sofre em relação a sua doença?”; "O que você faz para superar essas dificuldades?”. O objetivo da entrevista foi desvelar a perspectiva do paciente sobre sua enfermidade, expressando na própria voz sua linguagem popular. Intercaladas com as entrevistas abertas e aprofundadas, o paciente foi incentivado a discorrer livremente sobre seus sintomas, explicações etiológicas contando abertamente seus sofrimentos e estratégias para superá-los. Assim, a narrativa de enfermidade não reflete meramente um modelo ou representação estática da doença, mas permite que o informante ordene os acontecimentos, atribuindo os significados como julga relevante à sua vivência, defende Kleinman 16.

Contextualizamos e verificamos o discurso leigo e ampliamos a lente cultural com a observação-participante não-estruturada. Observamos os informantes-chave no contexto hospitalar durante as consultas com os profissionais de saúde do Programa de Reabilitação Pulmonar (pneumologista, fisioterapeuta, nutricionista, psicóloga, assistente social, terapeuta ocupacional e professora de Yoga), nas visitas com familiares, na prática de exercícios, nas reuniões de grupo e conversas informais com outros pacientes. Durante as visitas, observamos eventos como crise de dispnéia, interação com cuidadores, uso de remédios caseiros, medicamentos prescritos, aerossol e aparelhos portáteis de oxigênio, rotina doméstica e visitas de vizinhos.

As entrevistas foram gravadas e transcritas integralmente. Nomes fictícios preservaram o anonimato dos informantes. As observações foram anotadas num diário de campo e, posteriormente, em texto descritivo. Esse material foi organizado e codificado seguindo as etapas da análise de conteúdo 33 . Foram identificadas nove categorias temáticas, das quais centramos este artigo em três: (1) sintomas e seus significados; (2) dificuldades e sofrimentos com a doença pulmonar obstrutiva crônica; e (3) estratégias populares de enfrentamento da enfermidade.

Na análise e interpretação dos dados, inspiramo-nos na "interpretação semântica contextualizada” dos antropólogos Bibeau \& Corin 34 , interligando a experiência individual do pacientes aos sistemas de significação atribuídos; e as ações tomadas ou não, diante dos condicionantes estruturais. Finalmente, interpretamos os resultados à luz da Antropologia Médica. Desvelamos a racionalidade leiga 35 sobre sua enfermidade 13,16,17, a violência estrutural 36 , a crítica da conduta profissional 11, a desumanização institucional 24 e o agir popular diante da enfermidade, inclusive a resistência contra intervenções biomédicas 12,13.
O projeto de pesquisa foi aprovado pelo Comitê de Ética do Hospital de Messejana Dr. Carlos Alberto Studart Gomes sob o no. 224/05, em 31 de março de 2005.

\section{Resultados}

Sensações e sinais da doença pulmonar obstrutiva crônica e seus significados

Na percepção do paciente hospitalizado com doença pulmonar obstrutiva crônica no Nordeste brasileiro, são duas as principais sensações e sinais que preocupam: o "catarro" e o "cansaço". Gerado de uma gripe "mal curada", o "catarro" ou o acúmulo de secreção nos pulmões se apresenta como uma "baba clara" que com o tempo fica "seco", "preso" e "grudento" como "uma cola de sapateiro". Freqüentemente, se torna "esverdeada" ou "amarela" - "da cor do pinico" - após medicamento.

Apontando para o pinico amarelo no chão, ao lado do leito hospitalar, onde cuspiu um catarro "grosso" repetidamente, Sr. João, 69 anos, sapateiro com Ensino Fundamental incompleto, casado, nos comentou: "Quando eu tomo o remédio sai quase da cor do pinico ... mas tem hora que parece que tem um depósito de muita secreção ... quando o remédio está fazendo efeito mesmo é secreção demais!". Depois de sair amarela, volta novamente para a "baba clara": "Depois volta de novo pra baba ... quando passa o efeito melhora mais". O paciente avisa a esposa e filhas para se "afastar" do "pinico nojento", pois é visto como uma fonte de contaminação e transmissão da doença. Devido à sua natureza infecciosa, o estar próximo de uma pessoa com doença pulmonar obstrutiva crônica ou compartilhar utensílios pessoais são percebidos como ameaça às outras pessoas. Sr. João nos contou, com tristeza e os olhos cheios d'água, que não brinca com seus netos para não "passar" a doença.

O excesso de secreção pulmonar provoca a sensação de estar "entupido de catarro", não há lugar para o ar entrar ou sair do corpo. O paciente se sente "preso", "abafado" e "sufocado", experienciando um mal estar geral: "Quando eu me sinto muito cheio, quando tenho muita secreção, aí, eu me sinto entupido, né? ... tem aquele mal estar" (Sr. João). À medida em que "enche" ou "gruda o catarro no peito", sente a "falta de ar"; a respiração se torna mais difícil causando outro sinal de alerta - "o cansaço".

$\mathrm{O}$ verdadeiro perigo, conta os pacientes, é quando "o cansaço" - a dificuldade de respirar - passa para "uma crise”. O pânico, o desespero e “o sufoco que dá medo" tomam conta do corpo e 
da mente do paciente; o cuidador procura ajuda urgentemente. Vários fatores desencadeiam "o cansaço", levando a "uma crise" fulminante: um aumento de atividade física, um impacto forte ou choque emocional e o contato com a fumaça de cigarro, tanto pela inalação direta ou indiretamente com alguém que fuma. "As crises" freqüentes provocadas por vinte anos de fumo deixaram a dona-de-casa, Dona Rosa, 67 anos, semi-alfabetizada e viúva "cansada", deprimida e visualmente sofrida: "Sou muito triste de imaginar que eu vivo doente por causa de uma coisa que não me levou a nada ... porque fumar me levou a quê? Acabou com a minha vida, me levou a uma grande tristeza .... Acabou comigo". A freqüência pode ser tanta que um ano antes de receber o oxigênio Dona Rosa passou mais tempo internada do que em casa. Datas importantes como seu aniversário, dia das mães e Natal foram “celebradas” na cama hospitalar.

"O sufoco" na vida do paciente com a doença pulmonar obstrutiva crônica

A reação dos pacientes e familiares quando o profissional de saúde transforma suas queixas de sensações e sinais em diagnóstico de doença pulmonar obstrutiva crônica é, freqüentemente, "um choque". Ouvir que essa doença "esquisita" e desconhecida até então - a tal de doença pulmonar obstrutiva crônica - não tem cura e que para superá-la haverá despesas com oxigênio e medicamentos, além cuidados intensivos da família, provoca na vida de nossos pacientes empobrecidos um "sufoco" tão forte quanto a falta de ar. Todos os informantes experienciaram uma "reviravolta" em suas vidas depois do diagnóstico. Houve uma ruptura e/ou restrição de atividades cotidianas, uma inibição na vida íntima e sexual, um "vício" (dependência) no oxigênio e no cuidador e, pior, uma desmoralização da própria reputação e auto-estima de quem mais sofre com a doença. Marcos, 36 anos (aposentado por invalidez e casado), com doença pulmonar obstrutiva crônica grave associada à hipertensão pulmonar, esperando cirurgia para a retirada de uma parte do pulmão, se sentiu como um presidiário ao receber seu "sufocante" diagnóstico: "Os doutores cortaram um bocado de coisa minha, né?, ... mesma coisa de aprisionado. A lista que me deram do que eu podia e não podia fazer, o que eu podia e não podia comer ... aí, é muito triste. Triste demais".

A presença constante dos sintomas e sofrimentos rompe a vida cotidiana, interrompendo rotinas e modificando planos. Para mecânicos, caminhoneiros, vendedores de calçados ou carregador de cimento nas obras de construção, a do- ença pulmonar obstrutiva crônica leva ao abandono do trabalho e impossibilita o "sustento" da família. "Eu trabalhei muito em oficina de caminhão viajando, né, já fui também recepcionista de hotel, trabalhei em construção..." (Marcos). Atividades prazerosas exigindo esforço físico também foram condenadas ou severamente restringidas. Sem poder "curtir" a vida, sua existência perde sentido, lamenta Marcos: "Não posso mais trabalhar, dirigir ... dirijo, mas pouca coisa. Não posso viajar, não posso fazer o que eu gostava, ir à praia ... essas coisas que pra mim acabou-se. Não tem mais sentido, não. Nem vou que é pra não lembrar do passado". Para as mães de família, a doença pulmonar obstrutiva crônica impede zelar a casa, o marido, os filhos e a si mesma. As mudanças são progressivas e, com o tempo, deixam de realizar atividades essenciais - sair de casa, caminhar, fazer compras, trabalhar, ir à missa e à praia. Dona Maria, 67 anos, dona-de-casa, viúva; criou 12 filhos e sempre cuidou da casa sozinha. Com o aumento do "cansaço", o ritmo de suas atividades diminuiu a ponto de não realizá-las mais. "Eu me sinto muito cansada quando vou fazer qualquer atividade. Se eu for fazer até um café, eu canso .... Eu não faço nada só”. Após dedicar sua vida cuidando dos outros, essa "batalhadora" já não consegue cuidar de sua higiene pessoal: "Eu não agüento trocar de roupa ... tomar um banho sem cansar". Resta a ela sentar, "fazer um crochê ou um ponto de cruz" e esquecer seu sofrimento e cansaço.

A doença pulmonar obstrutiva crônica afeta as atividades físicas do casal, "sufocando" a relação sexual. As crises freqüentes de falta de ar, associadas à dificuldade de relaxar e dormir à noite, a restrição no esforço físico, a exigência de "fazer as coisas mais devagar", a dependência do oxigênio antes e/ou depois de fazer sexo e a "zuada" do concentrador, aparelho que fornece o oxigênio durante o sono, têm um efeito catastrófico para o casal: "esfria o clima" amoroso, rompe a intimidade e compromete o relacionamento. Nossos informantes relevaram momentos difíceis no casamento, com seus companheiros(as) e a doença pulmonar obstrutiva crônica. Dona Joana, 58 anos, dona-de-casa, casada há 41 anos, não consegue relaxar, abraçar e dormir com seu marido devido à secreção e falta de ar: "Eu não durmo direito. Passo a noite esperneando .... A minha cama amanhecia igual um ninho de galinha de eu não dormir direito ... cheia de catarro". O jovem Marcos, que antes da doença "vivia no mundo" e se orgulhava da longa lista de namoradas e vida sexual ativa, nos confessou privadamente: “Teve uma época no meu casamento que nós passamos mais de dois anos sem ter relação. Crise direto, direto, direto. Eu não procurava ela nem 
pra .... Momento ruim...". Recentemente, o casal desistiu do "sonho" de ter filhos devido à rápida evolução da sua doença e, segundo ele, as reclamações da esposa sobre o ruído do aparelho, as noites mal dormidas e sua preferência em dormir em quartos separados, vêm enfraquecendo, ainda mais, o relacionamento.

Ao mesmo tempo em que os laços de afetividade dos casais sofrem estresses pela doença, emergem dois tipos de dependências do paciente para sobreviver: dependência do cuidador e do oxigênio. O medo constante de uma crise inesperada associada à incapacidade para o autocuidado, deixa nosso paciente inseguro, vulnerável e impotente para agir em sua própria defesa. Assim, julga necessária a presença de alguém para auxiliar a ir ao banheiro, trocar de roupa ou levar ao médico, gerando um sentimento de dependência no cuidador. Só de pensar em depender dos outros deixa Dona Rosa deprimida e, em alguns momentos, revoltada com sua doença e impossibilidade de cura: "Pra uma pessoa como eu, que criei oito filhos, cuidava da minha casa e hoje me ver numa situação assim! É muito pesado. É muito triste a pessoa viver só dependendo dos outros sem poder fazer nada!". Viúva, Dona Rosa depende do filho para levá-la à missa e fazer compras, sentindo-se impotente diante da atual situação. Passa o dia "da cadeira pra cama" para não piorar o cansaço, administrando seus medicamentos. Antônio, 41 anos (aposentado por invalidez e casado), atormentado pelo medo de passar mal na rua durante uma crise e não chegar a tempo no hospital, conta com a esposa para acompanhá-lo. "Ando com a minha mulher do meu lado ... pra onde eu vou eu levo a mulher porque eu não ando sozinho, né? Ando um quarteirão, tenho que parar, me sentar. Não posso andar sozinho de jeito nenhum!". Para a esposa-cuidadora, o "sufoco" de ter o seu parceiro (e provedor) completamente dependente durante 24 horas, como um cão-guia, prejudicou seu desempenho no emprego e, conseqüentemente, a segurança financeira do casal.

Além de dependentes do cuidador, nossos informantes se tornam "viciados" no oxigênio para sustentar a vida. Cortar o "cordão umbilical" entre o tanque pesado de ferro e o paciente é, para eles, a morte encomendada. Metaforicamente, Dona Maria, viúva de um marido mulherengo, criada no interior trabalhando na roça, batiza de "cabresto" o suporte plástico do nariz que leva o oxigênio do tanque para seus pulmões "enfraquecidos”. Recorda-se dos cavalos do Nordeste para expressar o "sufoco" do aparelho. "O cavalo não fica preso naquele cabresto? Eu vou tirar esse cabresto! Dizer que não é um cabresto é, porque pra onde eu vou eu tenho que está encabrestada".
Outros pacientes se "viciam" nele como se fosse um melhor amigo ou amante, chamando-o carinhosamente de "amigo do peito". Devido ao ciclo vicioso - mais falta de ar, mais medo - o doente fica extremamente ansioso com a separação da fonte de vida. Dona Rosa, usa o oxigênio por quase um ano e já se sente "viciada": "Tiro de vez em quando ... porque, também, a gente se vicia, né? Eu não quero me viciar nisso aí, não!". Consciente de que "leva a vida" em função dele, tenta diminuir o número de horas de uso por dia recomendado.

Finalmente, o "sufoco" da doença pulmonar obstrutiva crônica desmoraliza o paciente, ameaçando sua auto-estima. Progressivamente, vêem sua reputação pessoal estigmatizada e desvalorizada nas interações sociais. A vida social ativa, as celebrações com amigos e os desejos dos amores acabam, lamentam nossos informantes. “Eu beijava na boca, o diabo a quatro! O pior é que agora não faço nada disso! Tão bom quando a gente fazia! Acabou-se foi tudo!" (Dona Joana). Tudo colabora para isolar o doente do mundo em que se engajava diariamente e de onde surgiu sua dignidade, respeito e prestigio pessoal. Antônio, que gostava de trabalhar e encontrar os amigos pra jogar futebol, declara uma desvalorização social perante seu estado de saúde. "O que mais me perturba? É a falta de ar ... e não poder fazer nada. Perturba demais. Não me sinto diminuído não, mas me sinto assim quase inválido".

Embora a respiração e a vida melhorem depois de "soprar" o ar puro, quando se retiram as bombas, inaladores ou o oxigênio os pacientes relatam que se sentem mais desesperados, deprimidos e diminuídos. Dona Maria, doente há 18 anos e oxigênio-dependente há seis, reclama de seu desânimo com a vida e sua baixa auto-estima, consciente de que não pode fazer nada sem o seu "vício": "Sem o oxigênio, eu não faço nada. Com ele eu ainda faço um ponto de cruz, um crochê. Mas sem ele eu não faço nada, nem andar .... Se eu tirar, eu não resisto nem cinco minutos meu cansaço". Os trabalhos manuais são vistos pela filha como a única forma da mãe esquecer, por algumas horas, o sufoco da doença.

\section{Sopro de vida: superar os danos da doença} pulmonar obstrutiva crônica

Para superar os danos da doença na pobreza urbana, os pacientes buscam saídas criativas - "um sopro de vida". Baseados numa racionalidade leiga e na medicina popular eclética, desenvolvem estratégias e ações para uma convivência mais saudável com a cronicidade.

Apesar das condições precárias de moradia da maioria dos pacientes, eles tomam cuidados 
para prevenir a transmissão da doença. Evitam o máximo contato com a fonte da infecção: "o catarro". Escondem dos visitantes o pinico, descartam lenços usados no lixo, separam e cobrem com pano prato, copo e talheres.

Para diminuir o catarro usam, além de medicamentos como Foraseq (Novartis Biociências S.A., São Paulo, Brasil), Aminofilina (União Química Farmacêutica Nacional S.A., São Paulo, Brasil), Atrovent e Berotec (Boehringer Ingelheim, São Paulo, Brasil), remédios caseiros como vários tipos de mel (abelha, abacaxi e mussambê): "Eu tomei muito mesmo uns tempos, mel de abacaxi com mel de abelha" (Dona Maria). Quando sente secreção nos pulmões, Dona Joana coloca a raiz do mussambê de molho numa panela de barro para fazer "o milagroso" mel. Para aliviar a tosse utilizam a inalação ou lavagem do rosto com água fervida de eucalipto, manjericão ou alfavaca, ou o uso de Vick Vaporub (Procter \& Gamble Brasil, São Paulo, Brasil) morno nos pés calçados com meia.

Buscam alívio para a crise do "cansaço que dá medo" nas terapias corporais populares, alterando a postura e respirando para "limpar" os pulmões e aumentar o fluxo de ar natural. Sr. João nos explica: "Quando eu acho que estou ficando cansado, eu já subo no terceiro andar, onde eu fiz um sótão bem arejado. Todo aberto. Aí, eu fico na janela, coloco os dois braços assim e fico ... recebendo ar, respirando. E parece que limpa. Fica bem normal".

Quando a falta de ar progride para a perigosa "crise", nossos pacientes empregam o autocontrole: manter a calma, respirar devagar e controlar o pânico. Tentam "distrair a cabeça" com pensamentos e atividades relaxantes e prazerosas: ouvir música, ler a Bíblia, ver televisão, costurar, cuidar das plantas. Recorrem ao aerossol e à "bombinha", contendo o problema em casa, sem procurar o hospital. Antônio, casado, participante do programa há quatro anos, emprega o autocontrole na hora da crise: "Não, não vamos pro hospital agora não. Tenha calma que não tem ninguém morrendo aqui pra ir pro hospital! Tenha calma".

Outros seguem a "teimosia" desafiando, resistindo e rejeitando regras impostas pelos mais velhos ou médicos. Saem à noite desacompanhados para namorar, tiram o oxigênio para conversar, andam no sol inalando poeira, caminham depressa para chegar mais rápido, porém cansados. Experienciam uma onda de liberdade do sufoco da doença pulmonar obstrutiva crônica, se sentem vivos e revigorados traçando seu modo de ser. Depois que participou do Programa de Reabilitação Pulmonar, Sr. João rompeu com o conselho dos vizinhos de que "deve ficar quie- tinho" quando sente falta de ar. Abraçou a estratégia oposta: "se mexer" para melhor respirar. Sobe a escada para chegar em casa e "dá uma volta" de bicicleta com o filho. Afirma: "A gente que tem problema respiratório, tem que se mexer (...) andar pra cá e pra lá. Não ficar parado .... Eu sinto que se você ficar parado, aí o cansaço chega mais".

Finalmente, a entrega espiritual é uma estratégia freqüente do nosso informante do Nordeste, região enraizada na religiosidade popular. $\mathrm{Na}$ hora da falta de ar, do desespero, se entregam "nas mãos de Deus". Desistem de "lutar" com as próprias armas e se rendem aos poderes divinos. Dona Joana "resiste" não somente à sua falta de ar, mas aos problemas da família, inclusive a bebida do filho, com a oração: "Eu rezo e peço muito a Deus força pra eu resistir àqueles problemas e defender daquilo que está acontecendo. Eu rezo muito o terço, rezo o terço da libertação, rezo o terço do Divino Espírito Santo, rezo o ofício ... e muitas orações". O terço da libertação ajuda a interceder por ela, por outra pessoa e também por sua família. É um sopro de vida espiritual que libera o aprisionamento da doença pulmonar obstrutiva crônica.

\section{Discussão}

Na conferência internacional Ethical Issues in the Measurement of Health \& the Global Burden of Disease, em abril de 2008 na Harvard University Medical School, Estados Unidos, foi discutido o esforço científico da Organização Mundial da Saúde (OMS) para medir "a carga global da doença” (Global Burden of Disease), permitindo um mapeamento dos focos de patologia e uma distribuição de recursos com mais eqüidade 37 . A grande busca é por medidas objetivas, quantificáveis e padronizadas que podem ser generalizadas para contabilizar a carga da doença no planeta. Portanto, há uma crítica crescente entre filósofos, psicólogos, psiquiatras e antropólogos que argumentam para a ampliação e contextualização desse cálculo 38,39; a "doença" deveria englobar a subjetividade da enfermidade, o "bem-estar" (well-being) e a experiência de adoecimento contextualizado no mundo moral local para medir os sofrimentos, preferências e prazeres humanos.

Os resultados deste estudo antropológico contribuem para uma reflexão crítica da medição da carga da doença global baseada somente na patologia biomédica. As narrativas testemunham o peso da doença pulmonar obstrutiva crônica na vida de exclusão social no contexto da pobreza urbana de Fortaleza, e os cuidados 
utilizados por leigos e pacientes para superar o "sufoco" e as limitações desta doença.

Aos poucos as sensações e sinais da doença pulmonar obstrutiva crônica surgiram na vida dos pacientes traduzindo significados importantes. O "catarro" e o "cansaço" causam o medo da morte iminente, a vergonha por estar em ambiente público e o mal-estar, muitas vezes incontrolável, sentimentos presentes em outros processos crônicos que traduzem sinais e significados que sufocam as pessoas $12,21,27,40,41$ , amedrontando os doentes 42 e determinando mudanças pessoais e familiares. Porém, pior do que estar preso com o "catarro" é sentir-se numa crise inesperada, às vezes de difícil controle, tendo como causa um problema de família, a própria doença ou outros aspectos emocionais também observados na asma, enfermidade com características semelhantes à doença pulmonar obstrutiva crônica 43.

O "sufoco" da doença se inicia no momento do diagnóstico quando é transmitido um "choque" ao doente e à família que, na maioria das vezes, apresentam receio do desconhecido e dificuldades de aceitação como qualquer outra enfermidade crônica 44 . Estudos realizados com a mesma população 45,46 mostram que o diagnóstico associado à progressão dos sintomas e sinais leva ao rompimento de atividades cotidianas, às limitações e privações de atividades antes realizadas com facilidade e prazer. A sexualidade, o trabalho, o lazer, as emoções, tudo sofre modificações e ajustes, alterando a qualidade de vida.

As crises tornam os dias mais pesados exigindo suportes físicos e pessoais, continuando o processo de dependência que se iniciou com a nicotina presente no cigarro. A história de dependência faz parte da vida desses indivíduos porque no processo de construção da enfermidade, na aquisição da dependência da nicotina, esta requer, muitas vezes, um tratamento cuidadoso para sua eliminação ${ }^{47}$. Pelo ciclo já descrito, a autoconfiança e auto-estima entram num processo de queda assustador para nossos informantes. Sentimentos de invalidez, diminuição, incapacidade e impotência machucam principalmente os homens que apresentam a concepção de provedor da casa e da família. A doença pulmonar obstrutiva crônica é tão assustadora e agressiva que nossos informantes criam estratégias e buscam recursos dentro do seu ambiente para superar as dificuldades, a exemplo de outros estudos 48,49 .

Tudo é válido para diminuir o sofrimento. $\mathrm{O}$ novo, o velho, o que surge inconscientemente ou por tentativas ou, simplesmente, pelo conhecimento do próprio corpo, como a consciência da respiração 50 . O sofrimento leva nossos pacientes a suplicar por ajuda, por uma solução para seu "maior problema", uma esperança, uma luz divina. A religiosidade como estratégia de enfrentamento é forte no Nordeste, onde as romarias, a oração do terço e a missa são praticadas, renovando e aumentando a fé. É a força para superar doenças e problemas pessoais 51,52,53.

As pessoas leigas constroem as próprias concepções e racionalidades acerca das doenças, baseadas no seu contexto, como observado com nossos informantes. Tais interpretações subjetivas, modelos explicativos populares da enfermidade (illness), são ainda diferentes dos modelos explicativos profissionais da doença (disease) 16. Assim, uma visão ampliada da doença pulmonar obstrutiva crônica exige que os profissionais compreendam as narrativas do adoecimento de seus pacientes. Nesse sentido, a enfermidade é a resposta subjetiva às suas experiências e da família dentro de seus ambientes 54,55 .

Os achados deste estudo permitiram aprender que a doença pulmonar obstrutiva crônica, como doença crônica, envolve uma teia de micro, meso e macro contextos, ou seja, o indivíduo, sua família, sua comunidade e, principalmente, sua cultura e suas crenças que não podem ser desprezadas no processo saúde-doença-cuidado. Nessa perspectiva, visualiza-se a crescente contribuição da Antropologia nas relações entre a pessoa que sofre e aquela que busca aliviar este sofrimento. O cálculo humano, portanto, jamais pode ser excluído na medição da carga global da doença no Nordeste brasileiro. 


\section{Resumo}

Trata-se de estudo antropológico de pessoas com a doença pulmonar obstrutiva crônica vivenciada na pobreza urbana de Fortaleza, Ceará, Brasil. De março a novembro de 2006, conduzimos com seis pacientes o estudo de casos, a entrevista etnográfica, a narrativa da enfermidade, e a observação participante no atendimento hospitalar e visitas domiciliares. Utilizamos a análise de conteúdo temática e a interpretação semântica contextualizada para interligar a experiência individual aos sistemas de significação, ações tomadas e condicionantes estruturais. Conclui-se que a doença pulmonar obstrutiva crônica provoca sensações, sinais e significados subjetivos. O diagnóstico torna a vida "um sufoco", surgindo limitações e privações de atividades laborais, sexuais, domésticas, familiares e de lazer. Evitar o contato direto com "o catarro" do doente, deixar de fumar ou diminuir a freqüência e evitar fumaça, tratar os sintomas com remédios caseiros e terapias corporais populares, manter a calma durante as crises, rejeitar restrições categóricas e impostas e entregar-se às forças espirituais são estratégias leigas para enfrentar o cansaço, a crise e a baixa auto-estima. A subjetividade da enfermidade, portanto, jamais pode ser excluída na medição da "carga global da doença" no nordeste brasileiro.

Doença Pulmonar Obstrutiva Crônica; Enfermidade; Antropologia Cultural

\section{Referências}

1. Barroso MGT, Vieira NFC, Varela ZMV. Educação em saúde: no contexto da promoção humana. In: Barroso MGT, Vieira NFC, Varela ZMV, organizadoras. Educação em saúde: no contexto da promoção humana. v. 1. Fortaleza: Edições Demócrito Rocha; 2003. p. $15-20$.

2. Bugge E, Higginson IJ. Palliative care and the need for education: do we know what makes a difference? A limited systematic review. Health Educ J 2006; 65:101-25.

3. Buss PM. Uma introdução ao conceito de promoção da saúde. In: Czeresnia D, Freitas CM, organizadores. Promoção da saúde: conceitos, reflexões, tendências. Rio de Janeiro: Editora Fiocruz; 2003. p. 15-38.

4. Czeresnia D, Freitas CM, organizadores. Promoção da saúde: conceitos, reflexões, tendências. Rio de Janeiro: Editora Fiocruz; 2003.

5. Secretaria de Políticas de Saúde, Ministério da Saúde. Projeto promoção da saúde: as cartas de promoção da saúde. Brasília: Ministério da Saúde; 2002.

6. Kerr J. Community health promotion: challenges for practice. London: Baillière Tindall; 2000.

7. Carvalho SR. Os múltiplos sentidos da categoria "empowerment" no projeto de Promoção à Saúde. Cad Saúde Pública 2004; 20:1088-95.

\section{Colaboradores}

J. M. S. Pinto foi autora da concepção do estudo, realizou a revisão da literatura, coleta e análise dos dados e redação inicial do artigo. L. J. E. S. Vieira participou das discussões dos dados e revisão final do artigo. M. K. Nations orientou as etapas da pesquisa e colaborou na redação do artigo.

\section{Agradecimentos}

À Fundação Cearense de Apoio à Pesquisa (FUNCAP) e ao Hospital de Messejana Dr. Carlos Alberto Studart Gomes pelo apoio na realização da pesquisa.
8. Becker D, Edmundo K, Nunes NR, Bonatto D, Souza R. Empowerment e avaliação participativa em um programa de desenvolvimento local e promoção da saúde. Ciênc Saúde Coletiva 2004; 9: 655-67.

9. Pitta F, Troosters T, Probst VS, Lucas S, Decramer M, Gosselink R. Possíveis conseqüências de não se atingir a mínima atividade física diária recomendada em pacientes com doença pulmonar obstrutiva crônica estável. J Bras Pneumol 2006; 32:301-8.

10. Miravitlles M. Avaliação econômica da doença pulmonar obstrutiva crônica e de suas agudizações: aplicação na América Latina. J Bras Pneumol 2004; 30:274-85.

11. Nations, MK, Gomes AMA. Cuidado, "cavalo batizado" e crítica da conduta profissional pelo paciente-cidadão hospitalizado no Nordeste brasileiro. Cad Saúde Pública 2007; 23:2103-12.

12. Nations MK, Monte CMG. "I'm not dog, no!": cries of resistance against cholera control campaigns. Soc Sci Med 1996; 43:1007-24.

13. Uchôa E, Vidal JM. Antropologia médica: elementos conceituais e metodológicos para uma abordagem da saúde e da doença. Cad Saúde Pública 1994; 10:497-504.

14. Lira GV, Nations MK, Catrib AMF. Cronicidade e cuidado: o que a antropologia médica tem a nos ensinar. Texto \& Contexto Enferm 2004; 13:147-55. 
15. Celli BR, MacNee W. Standards for the diagnosis and treatment of patients with COPD: a summary of the ATS/ERS position paper. Eur Respir J 2004; 23:932-46.

16. Kleinman A. The illness narratives: suffering, healing \& the human condition. New York: Basic Books; 1988.

17. Kleinman A. What really matters: living a moral life amidst uncertainty and danger. Oxford: Oxford University Press; 2006.

18. Geertz CA. Interpretação das culturas. Rio de Janeiro: Editora Guanabara Koogan; 1989.

19. Helman CG. Cultura, saúde e doença. Porto Alegre: Editora Artes Médicas; 1994.

20. Vasconcelos EM. Educação popular e a atenção à saúde da família. São Paulo: Editora Hucitec; 2001.

21. Arcanjo GN, Silva RM, Nations MK. Saber popular sobre dores nas costas em mulheres nordestinas. Ciênc Saúde Coletiva 2007; 12:389-97.

22. Farmer P. Infections and inequalities: the modern plagues. Berkeley: University of California Press; 1999.

23. Kleinman A. Patients and healers in the context of culture: an explanatory of borderland between anthropology, medicine, and psychiatry. Berkeley: University of California Press; 1980.

24. Gomes AMA, Nations MK, Luz MT. Pisada como pano de chão: experiência de violência hospitalar no Nordeste brasileiro. Saúde Soc 2008; 17:61-72.

25. Concone MHVB. Os sentidos da saúde: uma abordagem despretensiosa. In: Goldenberg P. Marsiglia RMG, Gomes MHA, organizadores. O clássico e o novo: tendências, objetos e abordagens em ciências sociais e saúde. Rio de Janeiro: Editora Fiocruz; 2003. p. 75-82.

26. Hammersley M, Atkinson P. Etnografía: métodos de investigación. Barcelona: Paidós; 1994.

27. Moreira TP, Nations MK, Alves MSCF. Dentes da desigualdade: marcas bucais da experiência vivida na pobreza pela comunidade do Dendê, Fortaleza, Ceará, Brasil. Cad Saúde Pública 2007; 23:1383-92.

28. Bernal C. Cidade extrapola seus limites. http:// adm.noolhar.com (acessado em 10/Out/2006).

29. Waiselfisz JJ. Mapa de violência dos municípios brasileiros. Brasília: Organização dos Estados Ibero-Americanos para a Educação, a Ciência e a Cultura; 2008.

30. Yin RK. Estudo de caso: planejamento e métodos. Porto Alegre: Bookman; 2001

31. Spradley JP. The ethnographic interview. New York: Holt, Rinehart and Winston; 1979.

32. Lira GV, Catrib AMF, Nations MK. A narrativa na pesquisa social em saúde: perspectiva e método. Rev Bras Promoção Saúde 2003; 16:59-66.

33. Bardin L. Análise de conteúdo. Lisboa: Edições 70; 1977.
34. Bibeau G, Corin EE. From submission to the text to interpretive violence. In: Bibeau G, Corin EE, editors. Beyond textuality: asceticism and violence in anthropological interpretation. Berlin: Mouton de Gruyter; 1995. p. 3-54.

35. Good BJ. Medicine, rationality and experience: an anthropological perspective. Cambridge: Cambridge University Press; 1994.

36. Farmer P. Pathologies of power: health, human rights, and the new war on the poor. Berkeley: University of California Press; 2003.

37. Murray CJL, Salomon JA, Mathers CD, Lopez AD. Summary measures of population health: concepts, ethics, measurement and applications. Geneva: World Health Organization; 2002.

38. Olsaretti S, Arneson RJ. Preferences and well-being. Cambridge: Cambridge University Press; 2006.

39. Kahneman DD, Norbert ES. Well-being: the foundations of hedonic psychology. New York: Russel Sage Foundation; 1999.

40. Nations MK, Calvasina PG, Martin MN, Dias HF. Cultural significance of primary teeth for caregivers in Northeast Brazil. Cad Saúde Pública 2008; 24:800-8

41. Calvasina PG, Nations MK, Jorge MSB, Sampaio HAC. "Fraqueza de nascença": sentidos e significados culturais de impressões maternas na saúde infantil no Nordeste brasileiro. Cad Saúde Pública 2007; 23: 371-80.

42. Santos LO. O medo contemporâneo: abordando suas diferentes dimensões. Psicol Ciênc Prof 2003; 23:48-9.

43. De Peuter S, Lemaigre V, Van Diest I, Van den Bergh O. Illness-specific catastrophic thinking and overperception in asthma. Health Psychol 2008; 27: 93-9.

44. Marques HHS, Silva NG, Gutierrez PL, Lacerda R, Ayres JRCM, DellaNegra $M$, et al. A revelação do diagnóstico na perspectiva dos adolescentes vivendo com HIV/AIDS e seus pais e cuidadores. Cad Saúde Pública 2006; 22:619-29.

45. Morano MTAP. A construção cultural da dependência e impotência: implicações para cuidados de pacientes com doença pulmonar obstrutiva crônica [Dissertação de Mestrado]. Fortaleza: Universidade de Fortaleza; 2001.

46. Fernández Vargas AM, Bujalance Zafra MJ, Leiva Fernández F, Martos Crespo F, García Ruíz AJ, Sánchez de la Cuesta y Alarcón F. Salud autopercibida, apoyo social y familiar de los pacientes con enfermedad pulmonar obstructiva crónica. Medifam 2001; 11:44-53.

47. Marques AC, Campana A, Gigliotti AP, Lourenço MTC, Ferreira MP, Laranjeira R. Consenso sobre o tratamento da dependência de nicotina. Rev Bras Psiquiatr 2001; 23:200-14. 
48. Steihaug S. Women's strategies for handling chronic muscle pain: a qualitative study. Scand J Prim Health Care 2007; 25:44-8.

49. Barnett M. Chronic obstructive pulmonary disease: a phenomenological study of patients' experiences. J Clin Nurs 2005; 14:805-12.

50. Petersen S, Orth B, Ritz T. Awareness of breathing: the structure of language descriptors of respiratory sensations. Health Psychol 2008, 27:122-7.

51. Faria JB, Seidl EMF. Religiosidade, enfrentamento e bem-estar subjetivo em pessoas vivendo com HIV/AIDS. Psicol Estud 2006; 11:155-64.

52. Santos EC, Koller SH, Pereira MTLN. Religião, saúde e cura: um estudo entre neopentecostais. Psicol Ciênc Prof 2004, 24:82-91.
53. Nations MK, Barreto A. Culture, saints and cures in the Sertão. In: Guerrant RL, Souza MA, Nations MK, editors. At the edge of development: health crises in a transitional society. Durham: Carolina Academic Press; 1996. p. 29-51.

54. Capra F. O ponto de mutação: a ciência, a sociedade e a cultura emergente. São Paulo: Editora Cultrix; 1982.

55. Kleinman A. Writing at the margin: discourse between anthropology and medicine. Berkeley: University of California Press; 1995.

Recebido em 27/Jun/2007

Versão final reapresentada em 09/Mai/2008

Aprovado em 19/Mai/2008 